\title{
Caring or collusion? Academic dishonesty in a school of nursing
}

Maureen Wideman

University of Ontario Institute of Technology

\begin{abstract}
Academic dishonesty is an issue that post-secondary institutions are having difficulty resolving. More than 100 studies have been conducted over the past 30 years, yet these studies have not provided data necessary to effectively address this problem. Indeed, research indicates that academic dishonesty is increasing. The purpose of this study was to determine the meaning of academic dishonesty as described and understood by nursing students at an Ontario university. Eleven students were interviewed to determine their perceptions regarding academic dishonesty. The data provided details of cheating behaviours and situations. Also significant were the students' descriptions of their life worlds, in which academic dishonesty plays a role. As a result, this study demonstrated that situational factors, such as a caring curriculum, heavy workload, faculty attitudes, and technology, had an impact on both why and how these nursing students were collaborating with each other and cheating.
\end{abstract}

\section{RÉSUMÉ}

La malhonnêteté académique est un problème que les établissements d'enseignement postsecondaire ont de la difficulté à résoudre. Plus de 100 études générales ont été effectuées au cours des 30 dernières années, mais elles n'ont pas produit de résultats concrets permettant de pallier ce problème. En fait, ces recherches indiquent que la malhonnêteté académique est en hausse. Le but de la présente étude était de déterminer la signification de la malhonnêteté académique telle que décrite et comprise par des étudiants en soins infirmiers d'une université ontarienne. Onze étudiants ont passé une entrevue pour évaluer leurs perceptions de la malhonnêteté académique. Les données fournies présentaient des détails 
sur des comportements et des situations associés à la tricherie. Également importantes pour l'étude, étaient les descriptions que les étudiants ont donné de leur monde, où la malhonnêteté académique est présente. Par conséquent, cette étude démontre que des facteurs situationnels, tels un programme éducatif bienveillant, une quantité importante de travail, le comportement des intervenants de la faculté et le recours aux technologies, ont eu un effet sur les raisons qui poussent les étudiants en soins infirmiers à collaborer entre eux et à tricher, de même que sur les façons d'y arriver.

\section{THE RESEARCH PROBLEM}

Working in faculty development for many years, I have had close contact with numerous faculty members from a wide variety of disciplines. Faculty members often discuss issues they have in the classroom, including academic dishonesty. However, the stories that I heard from nursing faculty regarding academic dishonesty were somewhat different than those of faculty members in other disciplines. For example, nursing students were cheating on a large scale; one incident involved upwards of 60 students. By comparison with students in other disciplines at this university, nursing students were highly skilled in the use of technology for cheating. Academic dishonesty was a serious concern to nursing faculty, who considered nursing, like other medical professions, to be an ethical profession, where the wellness of a patient may depend on the knowledge and skills of the attending nurse. As a result, I decided to conduct a study of nursing students' perceptions around academic dishonesty.

\section{THE STUDY}

The purpose of the study was to describe the meaning of academic dishonesty as perceived by the nursing students at a university in Ontario, Canada. Eleven students, some from each of the four years in a bachelor of science in nursing $(\mathrm{BScN})$ program, were interviewed to determine their perceptions regarding academic dishonesty within the nursing program, which included discussing their learning culture. The interviews averaged about two hours. The data suggested that for most of these students some acts of academic dishonesty were not considered cheating, but were seen as forms of caring or sharing. Many of the acts of academic dishonesty were conducted through the use of networked technology, as students worked together to communicate and share information and resources. They would also use their superior technology skills to manipulate or control their learning environment to ensure they could continue to collaborate with each other. As is the case in many collectivist cultures, the students in this program were extremely loyal to each other, and incidents of cheating were conducted to support group goals. In this program, it was often expected that students would cheat for the benefit of the group, but cheating for individual gain was frowned upon. 


\section{BACKGROUND}

The research into academic dishonesty conducted over the past few decades has been mainly quantitative in design, with students checking appropriate boxes to indicate their cheating behaviours (Ashworth, Bannister, \& Thorne, 1997). Mainly self-reported surveys, this research has returned huge amounts of data to confirm that cheating in post-secondary education appears to be on the increase (McCabe, 2009), yet this information has done little to illuminate aspects of the issue that will resolve cheating in schools. McCabe's study (2009) found that the level of collaborative cheating by nursing students was significantly higher than in other disciplines, whereas the level of individual cheating (using cheat sheets, for example) was significantly lower. Nursing is a profession where practitioners often find themselves in life-and-death situations. Previous research has demonstrated that cheating behaviours in the academic environment are often carried over into the workplace and could have a direct impact on the health of patients (Baxter \& Boblin, 2007; Gaberson, 1997).

The complexity of the issue of academic dishonesty is evident from the diversity of reasons student offer for why they cheat. Researchers argue students cheat because of ignorance (Jocoy, 2006; Pickard, 2006; Rader, 2002); poor professors and teaching environments (Anderman, 2007; Austin \& Brown, 1999; Bolkan, 2006; Hinman, 2002; Rabi, Patton, Fjortoft, \& Zgarrick, 2006; Sterngold, 2004); inadequate policies and penalties regarding academic dishonesty (Macdonald \& Carroll, 2006; Martin, 2005; Zobel, 2004); peer influence (Brown, 2002; Del Carlo \& Bodner, 2003; Myrick, 2004; Petress, 2003; Rabi et al., 2006); the desire to improve grades (Cummings, Maddux, Harlow, \& Dyas, 2002; Underwood \& Szabo, 2003); opportunity (C. DiCarlo, personal interview, April 12, 2007; McCabe \& Trevino, 1993); the availability of the Internet (Baum, 2005; Bruster, 2004); procrastination (Roig \& Caso, 2005); underdeveloped moral reasoning (Austin, Simpson, \& Reyen, 2005; Clark, 2003; Lewenson, Truglio-Londrigan, \& Singleton, 2005; Lindh, Severinsson, \& Berg, 2007; Szabo \& Underwood, 2004); the need to get a good job (McCabe, Trevino, \& Butterfield, 2001; Miller, Murdock, Anderman, \& Poindexter, 2007); and a cheating culture (Callahan, 2004; Langlais, 2006; Semple, Kenkre, \& Achilles, 2004; Vojak, 2007). In many cases, these results were obtained through self-reported surveys of students and faculty, some of them involving thousands of students. For example, in 2002 and 2003, the Centre for Academic Integrity at Duke University conducted a study with data collected from 54 colleges and universities (McCabe et al., 2006). Students have acknowledged cheating behaviours, they have checked the appropriate box for the reasons behind the cheating as defined by the researcher, yet the issue remains perplexing and unresolved. In a study of cheating among graduate business students, researchers were able to determine only 12 per cent of the variance in cheating, suggesting that the survey did not provide enough variables from which students could choose to explain their cheating behaviours (McCabe et al., 2006). 
In studies involving qualitative methods, researchers have determined that students did not have a deep understanding of what it means to have integrity in their school work (Ashworth et al., 1997; Clark, 2003; McCabe 1999). This finding is supported by two studies of cheating in laboratory environments conducted using observation and interviews. Students felt that copying each other's assignments might be considered cheating, but that assisting their peers to complete assignments was not, as students felt pressed for time to complete assignments (Del Carlo \& Bodner, 2004; Parameswaran \& Devi, 2006). Students appear to assume a survival mentality in their quest to complete assignments and see helping each other as akin to reaching over a cliff edge to assist a colleague who is at risk of dropping off. In some cases, this mentality includes an us-versus-them attitude. In his focus groups, Dawson (2004) found that students identified challenging the system as one reason for cheating. The concept of an authoritarian system that is repressive has been identified in other studies (Bernardi et al., 2004; Dawson, 2004; Wood, 2004) where being honest was seen as complying with rules that were deemed by students to be arbitrary. Although qualitative methods may not involve the large numbers of participants included in quantitative studies, the research provided by qualitative studies has, in part, informed our understanding of the issue by going beyond the statistics in an effort to find deeper meaning in the numbers.

Trust is the foundation of the relationship between nurse and patient. A 2003 survey of Canadians found that 94 per cent of the population trusts nurses (Canadian Press/Leger Marketing, 2003). Nurses' professional integrity is expected to be at the highest level and, as such, would attract students who share those values (Semple et al., 2004). The expectation of integrity does not seem to be borne out, as there appears to be a contradiction between student behaviour and institutional expectations. Paterson, Taylor, and Usick (2003) found that nursing faculty viewed plagiarism as a reflection of the low moral standards of students, and they expressed their concern about students in clinical practice and as researchers. However, in interviews, nursing students said they felt that plagiarism was situational and not an indication of a student's integrity (Paterson et al., 2003). Although lower moral standards are often cited by faculty as a reason for nursing students to cheat, there is research to suggest that students with high moral reasoning cheat as often as students with low moral reasoning (Cummings et al., 2002). However, other studies with nursing students reveal that neutralization is an important predictor of cheating behaviour (Daniel, Adams, \& Smith, 1994).

\section{METHODOLOGY}

The methodology used for this study was hermeneutic phenomenology. Phenomenology is a human science where the participant and the researcher engage in a discussion to reveal the meaning of a phenomenon as it is understood by the participant (van Manen, 1990). While traditional phenomenology focuses on the fundamental description of the phenomenon, hermeneutic phenomenology en- 
ables the interpretation of the description. For the purposes of this study, I sought commonalities and themes arising from the descriptions. The purpose of this hermeneutic phenomenological study was not to determine the cause of academic dishonesty, but to describe and interpret how the participating nursing students understood academic dishonesty based on their own lived experiences.

It was proposed that 10 to 12 full-time students be interviewed for this study, three students from each of the four years in a BScN program at an Ontario university. Volunteers were sought through an email sent to all nursing students from the university's health sciences program office. The email explained the research and the role of the participants. Students were to contact me directly to volunteer to participate. Once students responded to the initial email, a short questionnaire was sent to students requesting basic demographic data, such as year of schooling, age, sex, and cultural background. The plan was to number and categorize these surveys in order to randomly select the participants. However, because only 11 students came forward to participate in the study, no random selection was done. Two of the participants were in first year, two in second year, three in third year, and four in fourth year. The participants ranged in age from 18 to 50, with an average age of 25 . The group included one male and 10 females.

The method for data collection was in-depth, semistructured interviews of the 11 post-secondary nursing students. The interviews were digitally recorded, transcribed, and sent back to the participants for verification. Once the interview data were validated by the participants, the process of reduction began. In analyzing the data, the hermeneutic phenomenologist is searching for the hidden meaning behind the text (Maggs-Rapport, 2001). The transcripts were uploaded into the qualitative data analysis program QSR Nvivo 8. I reviewed them line by line and highlighted significant passages such as quotations, sentences, and words. The data were then manipulated by clustering statements and passages into themes or units of meaning. Eventually, 32 nodes or units of meaning were collected from the 11 transcripts.

\section{RESULTS}

For all the students interviewed, with the exception of one first-year student, this study revealed that academic dishonesty was part of their lived experience. If they were not participating in cheating, they had witnessed it in their post-secondary learning environment. Academic dishonesty is a complicated concept and it was apparent from this study that these nursing students had conflicting views. For example, all 11 students interviewed described themselves as honest students who did not cheat. Yet it can be demonstrated that all but two cheated on a regular basis.

\section{Understanding of academic dishonesty}

Like the subjects in previous research (Ashworth et al., 1997; McCabe, 1999; McCabe, 2005), the students in this study did not have an in-depth understanding 
of the issue of academic dishonesty, including which activities could be considered cheating, nor did they know their university's associated policies or their rights as students. Although the policy on academic dishonesty was included in every course syllabus, none of the students read the policy beyond the first week of class in first year. According to the students, faculty members did not spend much time discussing the policy or its implications. There was an expectation that the students were responsible for gaining that information.

Students also reported that the response from faculty members around academic dishonesty was inconsistent. Where one faculty member would not tolerate any form of plagiarism and would give offenders a mark of zero on their papers, other faculty members would have a different response. For example, in one class, a professor had students rewrite papers that had plagiarized passages. Another professor would reduce the grade of a paper, and still others would ignore the cheating altogether. This inconsistency contributed to the students' lack of understanding of academic dishonesty and its implications.

\section{Workload}

It became apparent to these students within their first few weeks of class that the workload in this $\mathrm{BScN}$ program was intense. Four of the students interviewed had previous science degrees, and all students said the workload was far heavier than anything they had experienced. According to Susan, a fourth-year student, most of the cheating was done on small assignments:

It's the more minor stuff, the day-to-day stuff. It's hard to plan out your semester to stay ahead and stay on top of stuff and actually have time to study for the major assignments and the small stuff too. I think the small stuff falls by the wayside to other things, be it they've left a big paper to the last minute and don't have time to study for the little quiz.

As a result, students begin to align themselves with others who can assist them through the course, year, and program. Serina, a first-year student, described her search for a study group in her first semester. When the first group she joined did not give her the support she required, she began to search for another:

So, I looked at everybody else in the classroom and it was like, "Who do I know? Who can I get to help me? Who can I trust to help me academically if I have any questions if I need to be in a group?" And I found those people. And I found them fairly quickly and it was great.

These academic groups appear to be very tight, with bonds that grow tighter as the students move through the program. In these groups, students share homework: for example, dividing the readings among the members with each reader providing summary notes to the others in the group. They assist each other with assignments, edit each other's work, and cover for each other if one student is not 
able to meet his or her obligations. They also cheat together. For example, many of the faculty members give weekly online quizzes to ensure students are completing the assigned reading. The quizzes are often copied by students and shared with the others in their group and in the course.

At times, loyalty can extend beyond the study group to include the entire class. For example, Susan stated, "Once one person gets a quiz ahead of time, then everybody's going to get it. We all see it - whether you want to use it or not is entirely up to you. Everybody has it." When quizzes are in class and password protected, the passwords are sent, through instant messaging or email, to students not able to attend the class. Academic papers are shared between students in different courses or semesters, and that favour is reciprocated. Students are on the hunt for " $A$ " papers to see formatting and other details. A fourth-year student, Jessica, said that when sharing papers, it was common for students to "lift a paragraph or two" and copy the references. Referencing using APA is difficult and time consuming. When students were writing on the same subject, they would simply copy another student's reference page.

Cheating to benefit the group was not an uncommon occurrence. For example, one student described an incident when a student jeopardized her own grade by stealing a midterm exam she had just written to provide it to students in two upcoming classes. There was no benefit to the student who stole the exam, but huge benefits to the other two classes who had yet to write it.

Although students described numerous incidents that involved cheating, few actually admitted that it was cheating. Previous research has found a correlation between neutralization and academic dishonesty (Albrecht, Wenz, \& Williams as cited in Bernardi et al., 2004). Neutralization, or deflecting blame, is a process of explaining or legitimizing one's dishonest behaviour, rendering it neutral or no longer dishonest. The students interviewed were neutralizing their cheating behaviours by using statements such as:

- It's just the way we do it.

- Everyone hates references and using APA.

- It wasn't stated on the syllabus.

- Not sure if it is cheating or not.

- Professors were asking for it.

- Even good people can do bad things.

- They can't kick me out because I'm paying for it.

While certain types of academic dishonesty were viewed as wrong - for example, cheating to improve one's personal performance - for the most part, these students were tolerant of others' cheating behaviours as long as they themselves were not negatively impacted by the cheating. 


\section{Stress}

Students reported high stress levels resulting in desperation that, according to the participants, can drive even the best student to cross the line into dishonesty. Stress may affect a person's ability to make a decision and assess risk (Beach \& Connolly, 2005). Students reported that there was pressure to achieve good grades in the program, with advantages such as research jobs, admittance into specialized courses, and better clinical placements for those who did so. Students in the study reported feeling pressure from parents to succeed in the program. They reported that their experiences in the clinical setting could be stressful, particularly when dealing with the death of a patient. Several students reported financial pressure; one student stated that her husband had to work extra shifts in order to pay for her education. The financial implications of failing were significant in that students failing a course may have to wait a year before that course is offered again, putting them behind their cohort. Students also reported that they were stressed by making the transition from high school to university. They felt unprepared for the workload and demands of the nursing program. As a result of the stress these students experienced, they had developed a number of coping mechanisms, some of which included academic dishonesty. Consciously or unconsciously, people develop coping methods to fulfill a need such as avoiding pain or sidestepping complications in their lives (Brill \& Levine, 2005). For the students in this nursing program, these coping methods included sharing papers, assignments, quizzes, answers, and reflective notes in an effort to assist each other through the program.

\section{Technology}

This study suggests that students were also cheating in reaction to a lack of power. Where students did have the upper hand was in their knowledge and experience in the use of technology. Students would use their superior technological skills to thwart efforts by faculty members to ensure a secure test environment. A faculty member who was not skilled in the use of technology was open to high levels of academic dishonesty. Mark, a second-year student, said he did not feel any guilt about students working together in groups to order to complete the online quizzes or other assignments. He stated that if the faculty member created the quiz in such a way as to make it so simple to cheat, then the faculty member should expect students would use the easiest method to complete it, even if it technically meant cheating.

The students described incidents when faculty members would try to put in place controls using technology; however, students would quickly and easily find ways around the barrier. This dance would continue until students could no longer use technology to gain an advantage. When that was the case, their cheating continued using traditional methods, such as telling each other what was on the test rather than using instant messaging. While most of the cheating was conducted through technology, it was apparent that even without the presence of technology, 
the cheating would continue. Students also commented that the level of cheating they witnessed was far lower at university, where they enjoyed a high-tech learning environment, than in high school, which was extremely low tech.

\section{Culture}

Language plays an important role in the development of culture (Triandis, 2001; Wells, 1994). When analyzing the transcripts, it became apparent that "caring" played a significant role in the lives of these students. They are learning through a "caring curriculum"; they study textbooks on the philosophy of caring; they incorporate and practise caring in their academic and clinical environments. It became apparent that parallels could be drawn between the philosophy of caring and academic dishonesty in this program. For example, caring nurses empathize with patients; they set aside judgments that might interfere with the care of patients; they do what they can to heal the physical and mental pain experienced by patients; they play a role in the recovery of the patient while respecting the autonomy of the patient (Watson, 1985). These caring traits were conspicuous when discussing the relationships these students had with each other and in the discussions surrounding academic dishonesty. One aspect of the study revealed that students were transferring the concept of caring from nursing situations to their fellow students: they commonly assisted fellow students who were at risk - how can one stand by and watch a fellow student fail? Caring and sharing with each other were not considered cheating.

It was apparent when analyzing the data that students had developed traits similar to those found within collectivist cultures. Although the participants live in an individualistic society (Canada), these students had developed customs and loyalties similar to those found within collectivist societies. For example, when discussing the work the students do within their academic groups, they demonstrated high levels of trust and loyalty. Students would complete each other's assignments if a fellow group member was unable to do so. In collectivist cultures, the goals of the group take priority over those of the individual (Triandis, 2001; Wells 1994). And although students work for individual marks, it was apparent that they worked closely together to ensure all members' marks were as high as they could be. Academic dishonesty was being committed but as a group endeavour, to assist others as much as oneself.

\section{DISCUSSION}

Social psychology (Kohn, 2007) and social constructivism (Vygotsky, 1978) recognize the impact of situation in one's ability to react and understand reality. Kohn suggests that cheating behaviours are a result of a flawed educational system rather than the character of its students (2007). In this study, the participants described acts of academic dishonesty but often framed them as caring and sharing with each other. Students were using cheating as a method of coping with their course 
loads. They were neutralizing the incidents by deflecting blame from themselves. They were demonstrating traits similar to those found within collectivist societies as they worked toward a group goal of successfully completing the program and becoming nurses. Academic dishonesty within the nursing program was not, for the most part, an individual endeavour but a collectivist one.

Students described how faculty members emphasize dishonesty when issues such as plagiarism are discussed. What is not discussed is what it means to be an honest student. Students described themselves as nursing students being taught how to be good nurses. They were not taught to be good students. Within postsecondary education, there is the assumption that students come to our schools with a complete understanding of what it means to be a successful and honest student. However, this study demonstrates that students' understanding of academic integrity is limited. The university and the nursing program should begin to create a culture that embraces academic integrity. As well, the students associate the consequences of cheating with getting caught, rather than with the potential deficit of knowledge or the impact that cheating could have in the future on patient care.

Faculty members are an important factor in understanding academic dishonesty. Many studies report that most faculty members believe that academic dishonesty is a student problem in that it is a result of low moral standards (Austin et al., 2005; Clark, 2003; Lewenson et al., 2005). Other studies would dispute this statement, because students with low moral reasoning are cheating as much as those with high moral reasoning (Cummings et al., 2002). The focus of academic dishonesty should shift from the characteristics of students to the situations where students find opportunities to cheat. As well, the participants in this study stated that faculty members' responses to incidences of cheating were inconsistent. This inconsistency contributes to students' confusion about what it means to be academically dishonest.

Although research into academic dishonesty has been intense for the past two decades, statistics show that the incidence of self-reported cheating is increasing (McCabe, 2009). The cheating problem has not improved, considering that the activities are taking place primarily in traditional, face-to-face classrooms. As classrooms and learning become more technologically sophisticated, the problem appears to be escalating as technology makes it easier for students to plagiarize or share information. Educators have been unable to resolve the problem of cheating in traditional learning environments, which makes the challenge in technological ones even more puzzling and confusing. There's little doubt that we are living through a revolutionary period in education, when technology has changed how students interact with the professor, the content, and each other. As such, using technological means to replicate traditional learning or assessment methods may not be the best way of using the technology. Faculty members who do not have a sophisticated knowledge of technology are leaving themselves open to dishonest practices by students. Rather than removing technology (students still cheat without technology), faculty members should take steps to become more knowledge- 
able about technology and how it can be successfully implemented in their teaching practices. Assessment methods need to be revisited, as traditional methods of assessment can be ineffective in a high-tech world.

Watson (1985) outlines two methods of intervention for assisting those under stress: interventions to change perceptions and interventions that change behaviours. To intervene to change perceptions, and therefore lower stress, she recommends developing teaching and learning strategies in combination with other supports as needed, such as counselling or emotional support. Teaching and learning strategies could include, for example, greater emphasis on integrity in academia; description of which acts or behaviours are considered cheating and which are not; strategies to improve academic skills; and strategies to cope in stressful situations. To intervene to change behaviours requires that the person learn "anticipatory coping" strategies (Watson, 1985, p. 261), which reduce stress by preparing for it. This two-pronged approach may be one part of a larger strategy for contending with academic dishonesty.

Students in the BScN program display tendencies similar to those found within collectivist cultures. Members of collectivist cultures put group goals ahead of individual goals. They are concerned about relationships. The students in this study displayed loyalty to the group when they assisted each other in the completion of assignments and quizzes. They refused to go against the "unwritten code" that says one does not report a fellow student for dishonesty, either in class or in clinical settings. The program should consider how collectivist cultures solve problems. Students should play a significant role in determining or recognizing the extent of the problem and its implications, and they should be the ones who determine the solutions. It should come from the bottom up rather than the top down. Academic dishonesty within the nursing program is not, for the most part, an individual endeavour but a collectivist one. Therefore the answers may rest with collectivist solutions, ones that recognize the importance of the relationships between students and the importance students place on preserving those relationships.

Although much research into academic dishonesty has been conducted, students are reported to be cheating at increasing rates. Honour codes, stiffer penalties, and notations on transcripts have not been effective in reducing the levels of academic dishonesty to any significant degree. Much of the research has been on the characteristics of cheating students. Perhaps the emphasis of the research needs to change so that researchers determine the situations in which students find they are driven to cheat or are able to cheat. The $\mathrm{BScN}$ program has opportunities to experiment with new learning techniques using technology. This is fertile ground for research that can return data on learning, assessment and academic dishonesty.

Hermeneutic phenomenology is concerned with understanding the phenomenon (Creswell, 2007; Scott \& Usher, 1996; van Manen, 1990). To understand the meaning of academic dishonesty as part of the lived experience of nursing students, it became necessary to examine their learning culture. While adding to the scholarship in this field, this study reveals the perceptions of these participating 
students at a particular time. Research trustworthiness can be established when others are able to transfer data to areas of similar characteristics or experiences (Creswell, 2007; Koch, 1994). This study may provide a foundation for research in other fields such as those dealing with patients or other caring professions.

Another area of interest could entail a qualitative study of business students. Research has shown that business students report a higher level of academic dishonesty than students in other disciplines (Allen, Fuller \& Luckett, 1998). Furthermore, the statements students use to justify dishonest behaviour in school have been equated to those used in business environments (Nonis \& Swift, 2001). Considering the world's economic situation and scandals involving large companies such as the financial sector collapse, an investigation into the attitudes and perceptions of business students and integrity might provide interesting insights.

The purpose of this study was not to justify student academic dishonesty, but to develop an understanding of the students' perceptions concerning academic dishonesty. In the effort to better understand academic dishonesty, it becomes important to examine the issue from different perspectives. This study focused on the students' perceptions of their lives and the role that academic dishonesty played in their learning experience. It is hoped that this study can assist in our understanding of the issue of academic dishonesty and the role situational factors, such as intensive post-secondary workload, can have on the issue.

\section{REFERENCES}

Allen, J., Fuller, D., \& Luckett, M. (1998). Academic integrity: Behaviors, rates, and attitudes of business students toward cheating. Journal of Marketing Education, 20, 41-52.

Anderman, E. M. (2007). The effects of personal, classroom and school goal structures on academic cheating. In Eric M. Anderman \& Tamera B. Murdock (Eds.), Psychology of academic cheating. (pp.87-106). Burlington, MA: Elsevier Academic Press.

Ashworth, P., Bannister, P., \& Thorne, P. (1997). Guilty in whose eyes? University students' perception of cheating and plagiarism in academic work and assessment. Studies in Higher Education, 22(2), 187-203.

Austin, J. M., \& Brown, L. D. (1999). Internet plagiarism: Developing strategies to curb student academic dishonesty. The Internet and Higher Education, 2(1), 21-33.

Austin, Z., Simpson, S., \& Reyen, E. (2005). 'The fault lies not in our students, but in ourselves': academic honesty and moral development in health professions education - results of a pilot study in Canadian pharmacy. Teaching in Higher Education, 10(2), 143-156.

Baum, J. J. (2005). CyberEthics: The new frontier. TechTrends, 49(6), 54-56.

Baxter, P. E., \& Boblin, S. L. (2007). The moral development of baccalaureate nursing students: Understanding unethical behaviour in classroom and clinical settings. Journal of Nursing Education, 46(1), 20-27. 
Beach, L. R., \& Connolly, T. (2005). The psychology of decision making: People in organization (2nd ed.). Thousand Oaks, CA: Sage Publications.

Bernardi, R. A., Metzger, R. L., Scofield Bruno, R. G., Wade Hoogkamp, M. A., Reyes, L. E., \& Barnaby, G. H. (2004). Examining the decision process of students' cheating behavior: An empirical study. Journal of Business Ethics, 50(4), 397-414.

Bolkan, J. V. (2006). Avoid the plague: Tips and tricks for preventing and detecting plagiarism. Learning \& Leading with Technology, 33(6), 10-13.

Brill, N., \& Levine, J. (2005). Working with people: The helping process. Boston, MA: Allyn \& Bacon.

Brown, D. L. (2002). Cheating must be okay - Everybody does it! Nurse Educator, 27(1), 6-8.

Bruster, B. (2004). Cut and paste from cyberspace: Competency's changing face. Delta Kappa Gamma Bulletin, Summer, 38-40.

Callahan, D. (2004). The cheating culture: Why more Americans are doing wrong to get ahead. Orlando, FL: Harcourt.

Canadian Press/Leger Marketing. (2003). How Canadians perceive various professions. Montreal, QC: Leger Marketing. Retrieved from http:/ / legermarketing.com

Clark, K. D. (2003). Understanding student perspectives on academic integrity and integrity in the workplace. Dissertation Abstract International: 65(01A).

Creswell, J. W. (2007). Qualitative inquiry \& research design: Choosing among five approaches (2nd ed.). Thousand Oaks, CA: Sage Publications.

Cummings, R., Maddux, C. D., Harlow, S., \& Dyas, L. (2002). Academic misconduct in undergraduate teacher education students and its relationship to their principled moral reasoning. Journal of Instructional Psychology, 29(4), 286-296.

Daniel, L. G., Adams, B. N., \& Smith, N. M. (1994). Academic misconduct among nursing students: A multivariate investigation. Journal of Professional Nursing, 10(5), 278-288.

Dawson, J. (2004). Plagiarism: What's really going on? TL Forum (2004). Seeking Educational Excellence. Proceedings of the 13th Annual Teaching Learning Forum, 9-10 February 2004. Perth: Murdoch University. Retrieved from http:// lsn. curtin.edu.au/tlf/tlf2004/ dawson.html

Del Carlo, D. I., \& Bodner, G. M. (2003). Students' perceptions of academic dishonesty in the chemistry classroom laboratory. Journal of Research in Science Teaching, 41(1), 47-64.

Gaberson, K. B. (1997). Academic dishonesty among nursing students. Nursing Forum, 32(3), 14-21.

Hinman, L. M. (2002). Academic integrity and the World Wide Web. Computers and Society, 32 (1), 33-42.

Jocoy, C. (2006). Plagiarism by adult learners online: A case study in detection and remediation. International Review of Research in Open and Distance Learning, 7(1), 1-17. 
Koch, T. (1994). Establishing rigour in qualitative research: The decision trail. Journal of Advanced Nursing, 19, 976-986.

Kohn, A. (2007). Who's cheating whom? Phi Delta Kappan, 89(2), 88-94.

Langlais, P. J. (2006). Ethics for the next generation. Chronicle of Higher Education, 52(19), B11.

Lewenson, S. B., Truglio-Londrigan, M., \& Singleton, J. (2005). Practice what you teach: A case study of ethical conduct in the academic setting. Journal of Professional Nursing, 21(2), 89-96.

Lindh, I.-B., Severinsson, E., \& Berg, A. (2007). Moral responsibility: A relational way of being. Nursing Ethics, 14(2), 129-142.

Macdonald, R., \& Carroll, J. (2006). Plagiarism - A complex issue requiring a holistic institutional approach. Assessment $\mathcal{E}$ Evaluation in Higher Education, 31(2), 233-245.

Martin, D. F. (2005). Plagiarism and technology: A tool for coping with plagiarism. Journal of Education for Business, 80(3), 149-152.

Maggs-Rapport, F. (2001). 'Best research practice': In pursuit of methodological rigour. Journal of Advanced Nursing, 35(3), 373-383.

McCabe, D. L. (1999). Academic dishonesty among high school students. Adolescence, 34(136), 681-687.

McCabe, D. L. (2005). It takes a village: Academic dishonesty and educational opportunity. Liberal Education, 91(3/4), 26-31. Retrieved from http:/ / www.aacu. org/liberaleducation/le-sufa05/le-sufa05feature2.cfm

McCabe, D. L. (2009). Academic dishonesty in nursing schools: An empirical investigation. Journal of Nursing Education, 48(11), 614-23.

McCabe, D. L., Butterfield, K. D., \& Trevino, L. K. (2006). Academic dishonesty in graduate business programs: Prevalence, causes and proposed action. Academy of Management Learning \& Education, 5(3), 294-305.

McCabe, D. L., \& Trevino, L. K. (1993). Academic dishonesty: Honor codes and other contextual influences. Journal of Higher Education, 64(5), 522-538.

McCabe, D. L., Trevino, L.K., \& Butterfield, K. D. (2001). Cheating in academic institutions: A decade of research. Ethics and Behavior, 11(220), 219-232.

Miller, A. D., Murdock, T. B., Anderman, E. M., \& Poindexter, A. L. (2007). Who are all these cheaters? Characteristics of academically dishonest students. In Eric M. Anderman \& Tamera B. Murdock (Eds.), Psychology of academic cheating. (pp.932). Burlington, MA: Elsevier Academic Press.

Myrick, F. (2004). Pedagogical integrity in the knowledge economy. Nursing Philosophy, 5, 23-29.

Nonis, S., \& Swift, C.O. (2001). An Examination of the Relation Between Academic Dishonesty and Workplace Dishonesty: A Multicampus Investigation. Journal of Education for Business, 77(2), 69-78. 
Parameswaran, A., \& Devi, P. (2006). Student plagiarism and faculty responsibility in undergraduate engineering labs. Higher Education Research \& Development, 25(3), 263-276.

Paterson, B., Taylor, L., \& Usick, B. (2003). The construction of plagiarism at a school of nursing. Learning in Health and Social Care, 2(3), 147-158.

Petress, K. C. (2003). Academic dishonesty: A plague on our profession. Education 123(3), 624-627.

Pickard, J. (2006). Staff and student attitudes to plagiarism at University College Northampton. Assessment \& Evaluation in Higher Education, 31(2), 215-232.

Rabi, S. M., Patton, L. R., Fjortoft, N., \& Zgarrick, D. P. (2006). Characteristics, prevalence, attitudes, and perceptions of academic dishonesty among pharmacy students. American Journal of Pharmaceutical Education, 70(4), A1-A8.

Rader, M. H. (2002). Strategies for teaching Internet ethics. Delta Pi Epsilon, 44(2), 73-79.

Roig, M., \& Caso, M. (2005). Lying and cheating: Fraudulent excuse making, cheating, and plagiarism. Journal of Psychology, 139(6), 485-495.

Scott, D., \& Usher, R. (1996). Understanding educational research. New York, NY: Routledge.

Semple, M., Kenkre, J., \& Achilles, J. (2004). Student fraud: The need for clear regulations for dismissal or transfer from healthcare training programmes for students who are not of good character. NTresearch, 9(4), 272-280.

Sterngold, A. (2004). Confronting plagiarism. Change, 36(3), 16-21.

Szabo, A., \& Underwood, J. (2004). Cybercheats: Is information and communication technology fuelling academic dishonesty? Active Learning in Higher Education 5(2), 180-199.

Triandis, H. C. (2001). Individualism-collectivism and personality. Journal of Personality, 69(6), 907-924.

Underwood, J., \& Szabo, A. (2003). Academic offences and e-learning: Individual propensities in cheating. British Journal of Educational Technology, 34(4), 467-477.

van Manen, M. (1990). Researching lived experience: Human science for an action sensitive pedagogy. Albany, NY: State University of New York Press.

Vojak, C. (2007). What market culture teaches students about ethical behavior. Ethics and Education, 1(2), 177-195.

Vygotsky, L. S. (1978). Mind in society: The development of higher psychological processes (M. Cole, V. John-Steiner, S. Scribner, \& E. Souberman, Eds.). Cambridge, MA: Harvard University Press.

Wells, G. (1994). The complementary contributions of Halliday and Vygotsky to a "language-based theory of learning." Linguistics and Education, 6, 41-90.

Watson, J. (1985). Nursing: The philosophy and science of caring. Niwot, CO: University Press of Colorado. 
Wideman, M. A. (2009). Caring, sharing, coping and control: Academic dishonesty and the nursing student (Doctoral dissertation). Retrieved from https://tspace.library.utoronto.ca/handle/1807/19139

Wood, G. (2004). Academic original sin: Plagiarism, the Internet, and librarians. Journal of Academic Librarianship, 30(3), 237-242.

Zobel, J. (2004). "Uni cheats racket": A case study in plagiarism investigation. In Raymond Lister \& Alison Young (Eds.), Computer Education 2004 - Proceedings of the Sixth Australasian Computing Education Conference, Dunedin, New Zealand, 18-22 January 2004.

\section{CONTACT INFORMATION}

Maureen Wideman

University of Ontario Institute of Technology

2000 Simcoe St. N.

Oshawa, ON

L1H 7K4

maureen.wideman@dc-uoit.ca

Maureen Wideman is an expert in teaching and learning, teaching with technology, curriculum development, academic integrity, and accessible learning environments. Maureen began her career in corporate communications. She then took her skills to the World Wide Web, where she was recognized by her peers with four national awards. Seeing the potential for the web as an educational tool, Maureen obtained a master of science in education, with a specialty in online teaching and learning, from California State University. She went on to complete her doctorate in education in curriculum, teaching, and learning. 